\title{
Permanent Magnet Synchronous Motors (PMSM). Parameters influence on the synchronization process of a PMSM
}

\author{
J. Rais ${ }^{1}$, M. P. Donsión ${ }^{2}$ \\ ${ }^{1}$ Department of Electromechanics and Power Electronics \\ Faculty of electrical engineering Plzeň., The University of West Bohemia in Pilsen \\ Univerzitni 8; 30614 Pilsen; Czech Republic \\ phone: +420604 743144, e-mail: jrais@sdutents.zcu.cz, \\ ${ }^{2}$ Electrical Engineering Department, Vigo University, Spain \\ Department of Electrical Engineering, University of Vigo, Campus of Lagoas Marcosende, 36310 Vigo (Spain), \\ IEEE, EA4EPQ and AEDIE member, donsion@vigo.es
}

\begin{abstract}
This work is deal with problems about PMSM. In the first part there is account working principle and design of PMSM. Below there is mathematic model of PMSM, which is used in calculation of behavior PMSM. The third part is deal with parameters influence on transient phenomenon, especially his starting and synchronization process. The last part observes parameters influence on the machine with help of simulator program PCSIM. There are four cases. The first case is Voltage Source Inverter applied to a PMSM, the second case is A Voltage Source Inverter controlled by a Pulse Width Modulation applied to a PMSM, third case is A Voltage Source Inverter with supply cable applied to a PMSM and the last case is Influence of quality of supplied electricity on the behaviour of PMSM
\end{abstract}

\section{Key words}

Permanent Magnet Synchronous Motor, DQ model, Electromagnetic torque, Voltage Source Inverter, PWM

\section{Introduction}

Permanent magnet synchronous motors are increasing applied in several areas such as traction, automobiles, robotics and aerospace technology. The power density of permanent magnet synchronous motor is higher than one of induction motor with the same ratings due to the no stator power dedicated to the magnetic field production. Nowadays, permanent magnet synchronous motor is designed not only to be more powerful but also with lower mass and lower moment of inertia.

We can't use typical model d-q. This model is uncoupled, linear and has constant parameter, applied to salient pole synchronous machines. It may be inadequate for accurate modeling characteristics prediction of permanent magnet synchronous motor of interior type. It leads below to important errors when we evaluate machine performance or calculate the control circuits.

The behavior of permanent magnet synchronous motor of the interior type can be rather different than expected using the conventional two axis theory. It is necessary to establish new models for this case. We must take into account the magnetic flux redistribution along the rotor iron placed between the magnets and the airgap.

We must into account the required accurate of the results also the reliability of testing procedures for determination of the machine parameters, when we develop permanent magnet synchronous motor model.

The conventional methods of testing for determination of synchronous machine parameters can not be applied in the case of permanent magnet machine. And this is why we use test procedures, which are differing from the classical methods applicable to wound field synchronous machines.

\section{DQ model for PMSM}

Figure 7 exhibits the substitution diagram of synchronous electric motor with permanent magnet in rotor. It is diagram of single phase, where $\mathrm{R}_{\mathrm{s}}$ is resistance of single phase in stator winding, $\mathrm{L}_{\mathrm{s}}$ is induction of stator winding. When the rotor is rotated, his permanent magnets generate magnetic field with magnetic flux $\Phi_{\mathrm{F}}$, thus the electric voltage induces in stator winding $U_{\mathrm{E}}$. But the voltage has opposite mind, than feeding voltage $U_{s}$.



Fig.1 Substitution diagram of PMSM 
We can deduce this model from common model of synchronous motor, where we take in reduce premise. We will go from substitution diagram form figure 1 .

Reduce premise are:

- feeding voltage has harmonic wave

- values of stator windings $\mathrm{R}$ and $\mathrm{L}$ are same for all winding and there are constant

- course of magnetic induction B is constant in the air-gap

- magnetic current is linear and losses in iron is ignored

- Induced voltage $U_{i}$ has harmonic wave

Equations for electric circuit:

$$
U_{1}^{S}=R_{s} \cdot I_{1}^{S}+\frac{d \Psi_{1}^{S}}{d t}
$$

where top index $S$ is variable in the stator coordinate system.

Now we can define coupled magnetic flux $\psi$ :

$$
\Psi_{1}^{S}=\phi_{F} \cdot e^{j \vartheta}+L_{s} \cdot I_{1}^{S}
$$

magnetic flux $\Phi_{F}$ is excited by permanent magnets in rotor and it transforms to stator coordinates. Both equations are transformed to coordinate system DQ, which is rotating same radian frequency like rotate magnetic field:

$$
\begin{aligned}
& U_{1}^{R}=R_{s} \cdot I_{1}^{R}+\frac{d \Psi_{1}^{R}}{d t}+j \omega \Psi_{1}^{R} \\
& \Psi_{1}^{R}=\phi_{F}+L_{s} \cdot I_{1}^{R}
\end{aligned}
$$

Now we can write equation in DQ form:

$$
\begin{aligned}
& u_{d}=R_{s} \cdot i_{d}+\frac{d \Psi_{d}}{d t}-\omega \cdot \Psi_{q} \\
& \Psi_{d}=L_{d} \cdot i_{d}+\phi_{F} \\
& u_{q}=R_{s} \cdot i_{q}+\frac{d \Psi_{q}}{d t}+\omega \cdot \Psi_{d} \\
& \Psi_{q}=L_{q} \cdot i_{q}
\end{aligned}
$$

The stator flux linkage is

$$
\psi_{S}=\sqrt{\psi_{d}^{2}+\psi_{q}^{2}}
$$

Electromagnetic torque of motor is deduced from equation:

$$
\begin{aligned}
& M_{E}=\frac{3}{2} \cdot p_{p} \cdot I_{m}\left\{\psi_{1}^{*} \cdot I_{1}\right\} \\
& M_{E}=\frac{3}{2} \cdot p_{p} \cdot\left(\Psi_{d} \cdot i_{q}-\Psi_{q} \cdot i_{d}\right)=\frac{3}{2} \cdot p_{p} \cdot\left[\phi_{F}+\left(L_{d}-L_{q}\right) i_{d}\right] i_{q}
\end{aligned}
$$

\subsection{A Voltage Source Inverter (VSI) applied to a PMSM}

\begin{tabular}{|c|c|c|c|c|c|}
\hline$R_{S}(\Omega)$ & $L_{d}(H)$ & Syn & $R_{S}(\Omega)$ & $L_{d}(H)$ & Syn \\
\hline Case 1 & \multicolumn{5}{|l|}{ Case 2 } \\
\hline 0.3 & 0.0029 & $\mathrm{~N}$ & 1 & 0.0029 & $\mathrm{P}$ \\
\hline 0.3 & 0.0034 & $\mathrm{~N}$ & 1 & 0.0034 & $\mathrm{P}$ \\
\hline 0.3 & 0.0045 & $\mathrm{P}$ & 1 & 0.0045 & $\mathrm{P}$ \\
\hline 0.3 & 0.01 & $\mathrm{P}$ & 1 & 0.01 & $\mathrm{P}$ \\
\hline 0.3 & 0.03 & $\mathrm{P}$ & 1 & 0.03 & $\mathrm{P}$ \\
\hline 0.3 & 0.1 & $\mathrm{~N}$ & 1 & 0.1 & $\mathrm{~N}$ \\
\hline Case 3 & & Case 4 & \\
\hline 2 & 0.0029 & $\mathrm{P}$ & 3 & 0.0029 & $\mathrm{P}$ \\
\hline
\end{tabular}

\begin{tabular}{|c|c|c|c|c|c|}
\hline 2 & 0.0034 & $\mathrm{P}$ & 3 & 0.0034 & $\mathrm{P}$ \\
\hline 2 & 0.0045 & $\mathrm{P}$ & 3 & 0.0045 & $\mathrm{P}$ \\
\hline 2 & 0.01 & $\mathrm{P}$ & 3 & 0.01 & $\mathrm{P}$ \\
\hline 2 & 0.03 & $\mathrm{~N}$ & 3 & 0.03 & $\mathrm{~N}$ \\
\hline 2 & 0.1 & $\mathrm{~N}$ & 3 & 0.1 & $\mathrm{~N}$ \\
\hline Case 5 & \multicolumn{5}{|l|}{ Case 6} \\
\hline 4 & 0.0029 & $\mathrm{P}$ & 5 & 0.0029 & $\mathrm{~N}$ \\
\hline 4 & 0.0034 & $\mathrm{P}$ & 5 & 0.0034 & $\mathrm{~N}$ \\
\hline 4 & 0.0045 & $\mathrm{P}$ & 5 & 0.0045 & $\mathrm{~N}$ \\
\hline 4 & 0.01 & $\mathrm{P}$ & 5 & 0.01 & $\mathrm{P}$ \\
\hline 4 & 0.03 & $\mathrm{~N}$ & 5 & 0.03 & $\mathrm{~N}$ \\
\hline 4 & 0.1 & $\mathrm{~N}$ & 5 & 0.1 & $\mathrm{~N}$ \\
\hline
\end{tabular}

Tab.1 Choice values of $R_{s}$ qhad $12 y$ (syn - synchronization, $N$-no possible, $P$ - possible)

When the machine has low value of resistance of stator winding, its behavior will change, even if it is small change direct-axes impedance. If the direct-axes impedance is very small or very high, the synchronous machine will not reach synchronism. The more we get nearer to up interval, where the machine can reach synchronism, that the time of standstill of speed and torque is longer (fig. 1). It takes few seconds, and that is why we can't use this machine in practice. Machine with low value of resistance of stator winding has less loss in the winding.

When value of resistance of stator winding raises, the machine can reach synchronism, even the machine has low value of direct-axes impedance.

When we raise again value of resistance of stator winding, the interval of direct-axis impedance, where the

\begin{tabular}{|c|c|c|c|c|c|c|c|c|c|c|c|}
\hline Rs & Ld & $\mathrm{Im}$ & $\mathrm{T}$ & IL & syn & Rs & Ld & $\mathrm{Im}$ & $\mathrm{T}$ & IL & syn \\
\hline 0.3 & 0.03 & 1.79 & 5 & 0 & $P$ & 0.3 & 0.06 & 1.79 & 5 & 0 & $P$ \\
\hline 1 & 0.03 & 1.79 & 5 & 0 & $P$ & 1 & 0.06 & 1.79 & 5 & 0 & $P$ \\
\hline 2.5 & 0.03 & 1.79 & 5 & 0 & P & 2.5 & 0.06 & 1.79 & 5 & 0 & $P$ \\
\hline 5 & 0.03 & 1.79 & 5 & 0 & $P$ & 5 & 0.06 & 1.79 & 5 & 0 & $P$ \\
\hline .5 & 03 & 1.79 & 5 & 0 & $P$ & 7.5 & 0.06 & 1.79 & 5 & 0 & \\
\hline
\end{tabular}
machine can reach synchronism, will decrease. If the value of resistance is very high and inductance very small, the machine can't reaches synchronism.

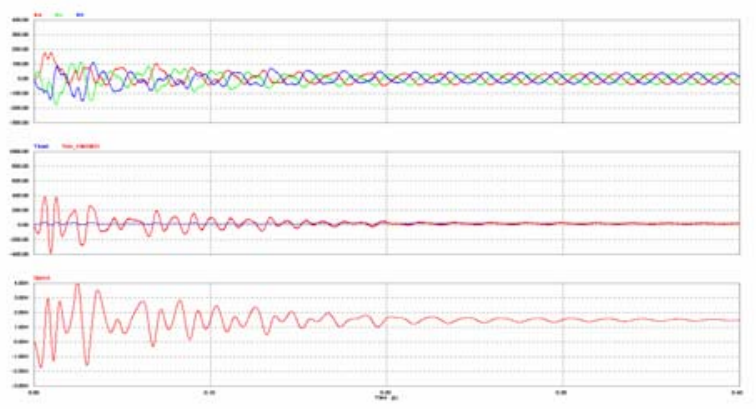

Fig. $1 R_{s}=0.3 \Omega, L_{d}=0.01 \mathrm{H}$ (Currents of the three phases charts for case, PMSM torque and constant load torque, PMSM speed versus time)

\subsection{A Voltage Source Inverter (VSI) controlled by a Pulse Width Modulation (PWM) applied to a PMSM}




\begin{tabular}{|c|c|c|c|c|c|c|c|c|c|c|c|}
\hline 10 & 0.03 & 1.79 & 5 & 0 & $P$ & 10 & 0.06 & 1.79 & 5 & & $P$ \\
\hline 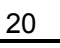 & 0.03 & 1.79 & 5 & 0 & $\mathrm{~N}$ & 20 & 0.06 & 1.79 & 5 & 0 & $\mathrm{~N}$ \\
\hline$s$ & Ld & $\mathrm{Im}$ & $\mathrm{T}$ & $\mathrm{IL}$ & syn & Rs & $\mathrm{Ld}$ & $\mathrm{Im}$ & $\mathrm{T}$ & $\mathrm{IL}$ & syn \\
\hline 0.3 & 0.03 & 1.79 & 10 & 0 & $\mathrm{~N}$ & 0.3 & 0.03 & 2.79 & 5 & 0 & $P$ \\
\hline 1 & 0.03 & 1.79 & 10 & 0 & $\mathrm{~N}$ & 1 & 0.03 & 2.79 & 5 & 0 & $P$ \\
\hline 2.5 & 0.03 & 1.79 & 10 & 0 & $\mathrm{~N}$ & 5 & 0.03 & 2.79 & 5 & 0 & $P$ \\
\hline 5 & 0.03 & 1.79 & 10 & 0 & $\mathrm{~N}$ & 10 & 0.03 & 2.79 & 5 & 0 & $\mathrm{P}$ \\
\hline 7.5 & 0.03 & 1.79 & 10 & 0 & $N$ & Rs & $\mathrm{Ld}$ & $\mathrm{Im}$ & $\mathrm{T}$ & $\mathrm{IL}$ & syn \\
\hline 10 & 0.03 & 1.79 & 10 & 0 & $\mathrm{~N}$ & 0.3 & 0.03 & 1.79 & 5 & 0.001 & $\mathrm{P}$ \\
\hline 20 & 0.03 & 1.79 & 10 & 0 & $\mathrm{~N}$ & 1 & 0.03 & 1.79 & 5 & 0.0 & $P$ \\
\hline Rs & Ld & $\mathrm{Im}$ & $\mathrm{T}$ & $\mathrm{IL}$ & syn & 2.5 & 0.03 & 1.79 & 5 & 0.001 & $P$ \\
\hline 0.3 & 0.03 & 2.79 & 5 & 0.001 & $P$ & 5 & 0.03 & 1.79 & 5 & 0.001 & $P$ \\
\hline 1 & 0.03 & 2.79 & 5 & 0.001 & $P$ & 10 & 0.03 & 1.79 & 5 & 0.001 & $\mathrm{P}$ \\
\hline 2.5 & 0.03 & 2.79 & 5 & 0.001 & $\mathrm{P}$ & Rs & $\mathrm{Ld}$ & $\mathrm{Im}$ & $T$ & $\mathrm{IL}$ & syn \\
\hline 5 & 0.03 & 2.79 & 5 & 0.001 & $\mathrm{~N}$ & 5 & 0.06 & 2.79 & 5 & 0 & $P$ \\
\hline 10 & 0.03 & 2.79 & 5 & 0.001 & $\mathrm{~N}$ & 5 & 0.06 & 2.79 & 5 & 0.0001 & $P$ \\
\hline $\mathrm{R}$ & $\mathrm{Ld}$ & $\mathrm{Im}$ & $\mathrm{T}$ & $\mathrm{IL}$ & syn & 0 & 0.06 & 2.79 & 5 & 0.001 & $\mathrm{P}$ \\
\hline 0.3 & 0.03 & 1.79 & 5 & 0.0001 & $P$ & Rs & $\mathrm{Ld}$ & $\mathrm{Im}$ & $\mathrm{T}$ & $\mathrm{IL}$ & syn \\
\hline 1 & 0.03 & 1.79 & 5 & 0.0001 & $P$ & 0.3 & 0.03 & 1 & 7 & 0 & $P$ \\
\hline 2.5 & 0.03 & 1.79 & 5 & 0.0001 & $P$ & 1 & 0.03 & 1 & 7 & 0 & $P$ \\
\hline 5 & 0.03 & 1.79 & 5 & 0.0001 & $P$ & 2.5 & 0.03 & 1 & 7 & 0 & $\mathrm{P}$ \\
\hline 10 & 0.03 & 1.79 & 5 & 0.0001 & $\mathrm{P}$ & 5 & 0.03 & 1 & 7 & 0 & $P$ \\
\hline & & & & & & 10 & 0.03 & 1 & 7 & 0 & $\mathrm{P}$ \\
\hline
\end{tabular}

Tab. 2 Choice values of $R_{s}, L_{d}, I_{m}, T$ and $I_{L}\left(I_{m^{-}}\right.$Moment of Inertia of the PMSM, T- Constant Torque, $I_{L^{-}}$Moment of Inertia of the load, $N$-no possible, $P$-possible)

When we use a voltage source inverter (VSI) controlled by a pulse width modulation (PWM) applied to a PMSM, the values direct-axes impedance and resistance of stator winding haven't so big influence on the behavior of machine. Other way, when we used only VSI applied to a PMSM, the values had big influence on the behaviour of machine.

In the case 1 we can see, that PMSM can reach synchronism in almost all values. Only in the measurement, where is used $\mathrm{R}_{\mathrm{s}}=20 \Omega$, the machine can't reach synchronism, because the resistance of stator is so big. This resistance isn't good for practice. We can observe the difference among resistance of stator winding only on the beginning of starting process. The steady state is same for all resistance (without big resistance $20 \Omega)$.

In the case 2 , where we change direct-axes impedance, we can observe, that the machine has same behavior like in the case 1 . So direct-axis impedance hasn't so big influence on the behavior of machine like resistance of stator winding.

In the case 3 , we increase constant torque. Moment of inertia of PMSM and loud are still same like previous cases. This torque is so big and the machine can't reach synchronism. The speed decreases. Even the change of stator winding resistance hasn't helped. (Figure 2)

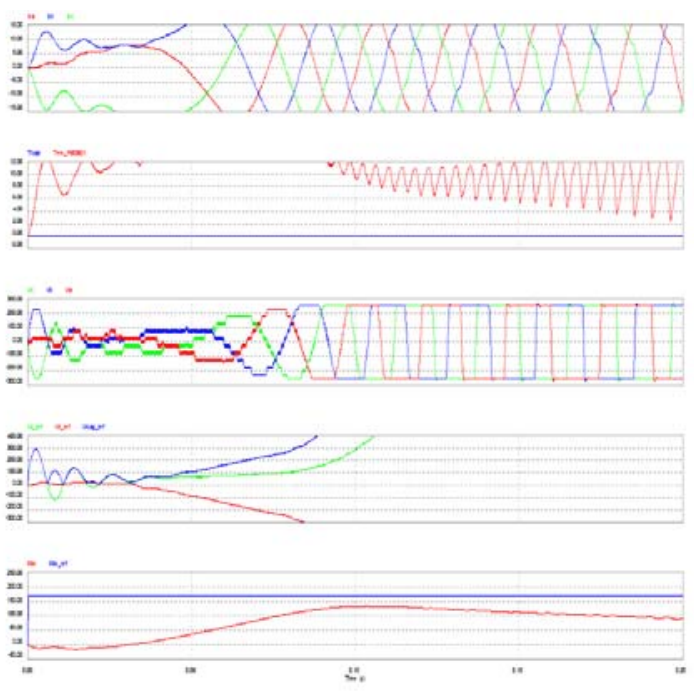

Fig. $2 R_{s}=2.5 \Omega, L_{d}=0.03, I_{m}=1.79, T=10, I_{L}=0$, syn $=n p$ (Currents charts of the three phases, Charts of the PMSM torque and constant load torque versus time, Voltage charts of the three phases, Chart of the reference voltages Vd, Vq and Vmag, PMSM simulation speed and reference speed versus time)

In the case 4 , we return value of constant torque back on the value 5 and we change moment of inertia of the PMSM. Under folloving values the time of standstill is longer. For example in the figure 3 we can observe how the time of standstill was long, before the machine can reach synchronism. When we change stator winding resistance, the behaviour changes only on the top of the starting process. If we use smaller stator winding resistance, we obtain smaller overshoot.

In the next case 5, we keep same values like case 4 , we increase only moment of inertia of load. When we use big stator winding resistance $10 \Omega$, the overshoot on the top is very big and time of standstill is so long. And this is why, the machine can't reach synchronism. When we use smaller stator winding resistance, the time of standstill decreases and size of overshoot decreases too.
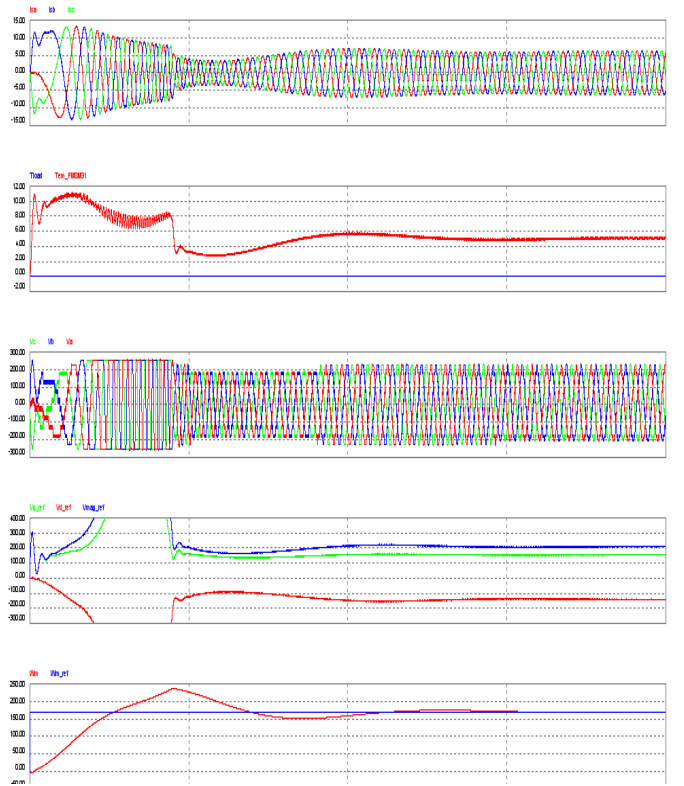
Fig. $3 R_{s}=10 \Omega, L_{d}=0.03, I_{m}=2.79, T=5, I_{L}=0$, syn $=p$ (Currents charts of the three phases, Charts of the PMSM torque and constant load torque versus time, Voltage charts of the three phases, Chart of the reference voltages Vd, Vq and Vmag, PMSM simulation speed and reference speed versus time)

In cases 6 and 7, we decrease moments of inertia of PMSM and load. Machine due to can reach synchronismu for all values in these cases.

In case 8 , we can observe influnce moment of inertia of load on the behavior of machine. Small variance of moment of inertia of load hasn't so big influence on behavior of machine. But if the varince will be big, the overshoot is longer and time of standstill is longer too.

\subsection{A Voltage Source Inverter (VSI) with supply cable applied to a PMSM}

We neglected inductive reactance and resistance of supply cable in the previous measurements (VSI, VSI controlled by PWM). We took this supply like ideal in these cases. This means, that the resistance and inductive reactance are zero. Ideal wire doesn't exist in the practice. Every wire has its impedance.

When we use short cable $\left(10 \mathrm{~m}, \mathrm{R}=0,0469 \Omega, \mathrm{X}_{\mathrm{L}}\right.$ $=0,00099 \Omega$ ), we can observe, that this small impedance of system hasn't influence on the PMSM. Machine has same influence like case with ideal wire.

We use cable length $3 \mathrm{~km}$ for last measurement. This cable has resistance $14,097 \Omega$ and inductive reactance $0,2997 \Omega(0,93 \mathrm{mH})$. This impedance is so high, that it is problem to get the machine to synchronism (fig 4). PMSM can reach synchronism only when we use values $R_{s}=0,3 \Omega$ and $L_{d}=0,01 H$.

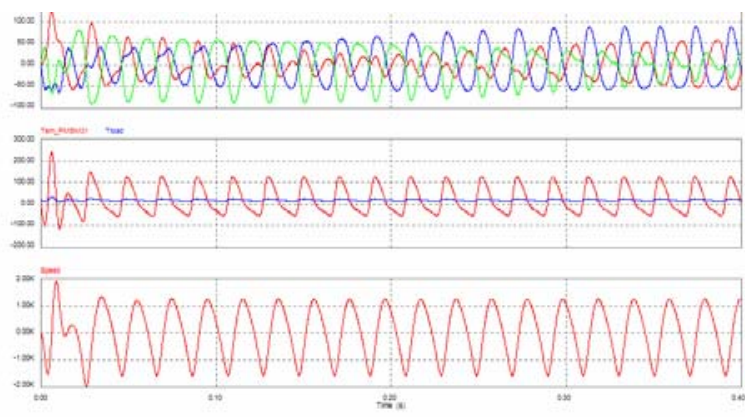

Fig. $4 R_{s}=1 \Omega, L_{d}=0.01 \mathrm{H}$ (Currents of the three phases charts for case, PMSM torque and constant load torque, PMSM speed versus time)

\subsection{Influence quality of supplied electricity on the behavior of PMSM}

In these measurements we deal with Influence of quality of supplied electricity on the behavior of PMSM. Quality parameters are many. We choose voltage asymmetry, voltage variations and network frequency for our measurements. This is task for VSI, which should watch on the quality for supply of machine.
Change network frequency hasn't influence on the behavior of PMSM, because the inverter can make right frequency for supply of machine.

In overvoltage $+10 \%$ the machine can reach synchronism in all cases. It wasn't in undervoltage $-10 \%$. PMSM with values $L_{d}=0.01 \mathrm{H}$ and $R_{s}=5 \Omega$ can't reach synchronism, because the stator winding resistance is big. The overvoltage is better for machine than undervoltage. In undervoltage the time, when the machine reach synchronism, is longer than time at overvoltage. If we use pulse rectifier instead of ordinary diode rectifier, we would eliminate this difference and the motor would reach synchronism in all case even will be higher undervoltage.

We changed voltage in one phase in value $552 \mathrm{~V}$ $(1 \%), 500 \mathrm{~V}(10 \%)$ and $400 \mathrm{~V}(28 \%)$ for creation asymmetry voltage.

In the first measurement $(552 \mathrm{~V})$, we are in permissible allowance, which is shown in norm for asymmetry voltage. The behavior of PMSM doesn't change in this case.VSI can make same voltage as when we use symmetry voltage for supply of VSI.

In the second measurement $(500 \mathrm{~V})$, we can observe difference in fig. 5. The size of peak-to-peak amplitude of speed is about $100 \mathrm{rpm}$. This peak-to-peak amplitude doesn't change in the future. And that is why, the machine can't reach the synchronism.

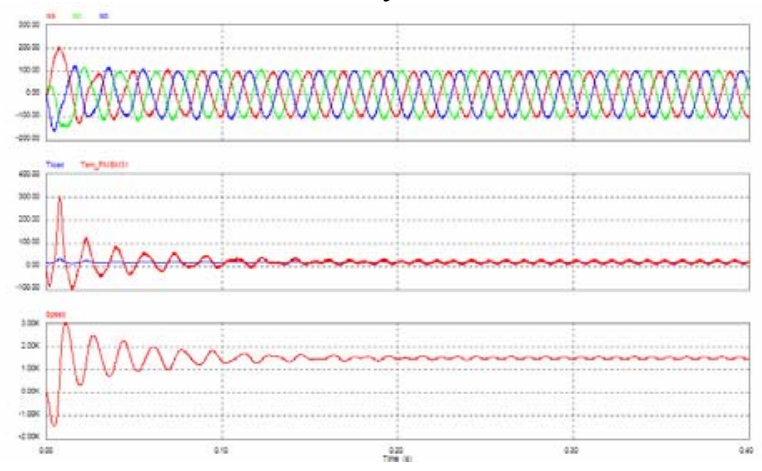

Fig. $5 R_{s}=1 \Omega, L_{d}=0.0045 \mathrm{H}, U_{u}=500 \mathrm{~V}$

In next measurement, we change the voltage in value $400 \mathrm{~V}$. Graphs of speed, torque and current are similar as previous measurement, only the peak-to-peak amplitude increases in $300 \mathrm{rpm}$.

When we increase stator winding resistance, the change of behavior of PMSM is very little. When we increase direct-axes impedance, the peak-to-peak amplitude increase too and curve of current is deformed.

In experiment, when VSI is supplied by 2 phase voltage, the curve of current is very deformed, that is why we can't apply this current for PMSM

\section{Conclusions}

The conclusion of VSI applied to PMSM is: When value of resistance of stator winding raises, the machine can reach synchronism, even the machine has low value of direct-axes impedance. When we raise again value of resistance of stator winding, the interval of direct-axis impedance, where the machine can reach synchronism, will decrease. If the value of resistance is very high and inductance very small, the machine can't 
reaches synchronism. When we increase stator winding resistance and d-axis inductance, we can observe, that the current form VSI decreases up to $50 \%$. Advantages of this control are his simplicity and his absence of PWM.

It is very difference, when we use VSI controlled by PWM applied to a PMSM, because in this case the values of stator winding resistance and directaxes impedance haven't so big influence on the behavior of PMSM.

When the impedance of circuit is so high, it is problem to get the machine to synchronism. PMSM can reach synchronism only when we use values $R_{s}=0,3 \Omega$ and $\mathrm{L}_{\mathrm{d}}=0,01 \mathrm{H}$.

We simulated change of network frequency. This change hasn't influence on the behavior of PMSM, because the inverter can make right frequency for supply of machine. If we use pulse rectifier instead of ordinary diode rectifier, we would eliminate influence on the voltage variation and the motor would reach synchronism in all case even will be higher undervoltage. The last experiment shows, that two-phase supplied id impossible.

All four measurements show, that when the machine has good design, so it can reach synchronism in most adverse operational situation.

\section{References}

[1] Motores Sinchrones de Imanes Permanents, Manuel Pérez Donsión, Manuel A. Fernandéz Ferro, 1990 Universidade de Santiago de Compostela

[2]Elektrické pohony pro dynamicky náročné aplikace, Martin Diblík, 2006 Technická univerzita v Liberci

[3]Permanent Magnet Synchronous Machine Model for Real-time SimulationA. B. Dehkordi, A. M. Gole, T. L. Maguire 2005, International Conference on Power System Transients in Montreal

[4]Direct Torque Controlof a Permanent Magnet Synchronous Motor,David Ocen, 2005 Stockholm 